\title{
GERMINAÇÃO DE SEMENTES E CRESCIMENTO INICIAL DE PLÂNTULAS DE INGÁ-MIRIM - Inga laurina (S W.) Willd - UTILIZADA NA ARBORIZAÇÃO URBANA DE RIO BRANCO, ACRE
}

\author{
João R. A. Leão ${ }^{1}$; João P. da C. Lima ${ }^{1}$; Stoney do N. Pinto ${ }^{1}$; Ary V. de Paiva ${ }^{2}$
}

\section{RESUMO}

A inga-mirim é uma espécie nativa da Floresta Amazônica com potencial para arborização urbana. Com o objetivo de estudar a germinação e crescimento inicial de plântulas desta espécie, para posterior propagação, realizou-se um experimento em casa de vegetação em temperatura ambiente e com irrigações periódicas. O delineamento experimental utilizado foi inteiramente casualizado, com quatro tratamentos e quatro repetições com 25 sementes em bandejas de plástico com 25x39x7,5 cm. Os resíduos agroflorestais testados como substrato foram casca de castanha-do-brasil triturada, casca de amendoim triturada, resíduo de açaí peneirado e areia como testemunha. Após a germinação das sementes foram analisadas porcentagem de germinação, índice de velocidade de germinação, peso fresco e seco da parte aérea e da raiz, comprimento da parte aérea e radicular, número de folhas e de folíolos. Através da análise de variância e Teste de Tukey a 5\% de probabilidade verificou-se que os substratos testados proporcionaram a mesma porgentagem de germinação às sementes e índice de velocidade de germinação, porém o substrato resíduo de açaí proporcionou o melhor resultado para comprimento da parte aérea e o substrato areia para matéria verde da parte aérea, número de folhas e folíolos, mostrando-se promissor para propagação e maior vigor de plântulas desta espécie.

Palavras-chave: Sementes florestais; Resíduo agroflorestal; Viveiro; Espécie nativa.

\section{SEED GERMINATION AND INITIAL GROWTH OF SEEDLING OF INGÁ-MIRIM - Inga laurina (S W.) Willd - USED IN URBAN FLORESTRY OF RIO BRANCO, ACRE}

\begin{abstract}
Inga-mirim is a native specie to the Amazon Rainforest with potential for urban forestry. Aiming to study the germination and initial growth of seedlings for subsequent propagation, was carried an experiment in greenhouse at ambient temperature with periodic irrigations. The experimental design was completely randomized with four treatments and four replicates with

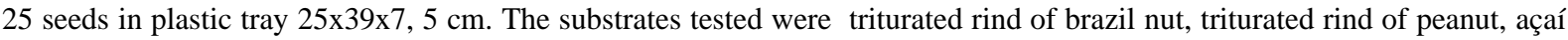
residue sifted and sand as a witness. After germination of seeds, there were analyzed germination percentage, speed germination index (SGI), fresh weight and dry of shoot and root, length of shoot and root, number of leaves and leaflets. Through the analysis of variance and Tukey test at 5\% probability it was found that all substrates afforded the same percentage of showed seed germination and speed rate of germination, but the substrate açaí residue highest values for shoot length and the substrate sand for fresh mass of the shoot, showing promising propagation and greater vigor of seedlings.
\end{abstract}

Keywords: Forest seeds; Nursery; Agroforestry residue; Native species.

1. Bolsistas CNPq, graduandos em Engenharia Florestal, Centro de Ciências Biológicas e da Natureza, Universidade Federal do Acre, Rio Branco, e-mail: ricardo.leao@ac.gov.br;jp_potis@hotmail.com

2 Eng. Agrônomo, D. Sc. em Recursos Florestais, Diretor do Parque Zoobotânico/UFAC, Prof. do Centro de Ciências Biológicas e da Natureza, Universidade Federal do Acre, Rio Branco, e-mail: aryvieira1@hotmail.com 


\section{INTRODUÇÃo}

O cenário das paisagens florísticas nos projetos de arborização, urbanização e paisagismo no Brasil são escassos referente à uniformidade e ao número reduzido de espécies arbóreas utilizadas que geralmente são exóticas. Para encontrar uma maior diversidade de espécies é necessária a exploração da riqueza da flora local com utilização de espécies nativas (MELO et al., 2008). De acordo com Jacinto (2001) a arborização contribui para a efetivação do potencial ecológico, recreativo, produtivo, estético e paisagístico, tendo, portanto, considerável influência sobre as condições ambientais urbanas.

A contribuição da vegetação urbana é significativa no que se refere à melhoria da qualidade do ambiente, pois a arborização nas ruas, praças, jardins e parques acrescentam vários benefícios como o resfriamento do ambiente, proteção contra ação dos ventos, alimentação e abrigo para avifauna, conforto térmico, beleza paisagística com importantes ganhos estéticos, culturais e ambientais (GODOY, 1995).

A Inga laurina (S W.) Willd é uma espécie ideal para arborização urbana, porque tem uma excelente adaptação ao meio urbano e tem a característica de manter suas

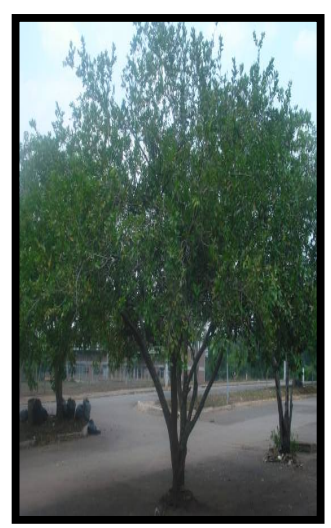

Figura 1. Estacionamento do curso de Engenharia Florestal, Campus/UFAC arborizado com ingá-mirim

Figure 1. Parking of Forest Engineering Course/UFAC folhas durante o período da seca. Desta forma, a sua copa proporciona uma área considerável de sombra (Figura 1 e 2). Agregado a isto, a ingá-mirim fornece frutos doces de polpa branca, consumidos pela fauna, inclusive pelo homem.

É uma árvore pertencente à família das Leguminosae e subfamília Mimosoideae, conhecida popularmente como ingá-mirim, ingá-branco e ingá de macaco, apresenta de 10 a 20 metros de altura, com uma copa ampla e baixa. As folhas são compostas (Figura 3), com floração de agosto a setembro e frutificação (Figura 4) a partir de novembro. A distribuição fitogeográfica desta espécie é ampla, a região amazônica é detentora de grande diversidade do gênero Inga, compreendendo aproximadamente 350 espécies, com predominância destas principalmente em áreas neotropicais. (LORENZI, 2002). Seus galhos são resistentes, não se rompendo facilmente pelo vento e suas raízes não são superficiais, não sendo observados danos às calçadas.

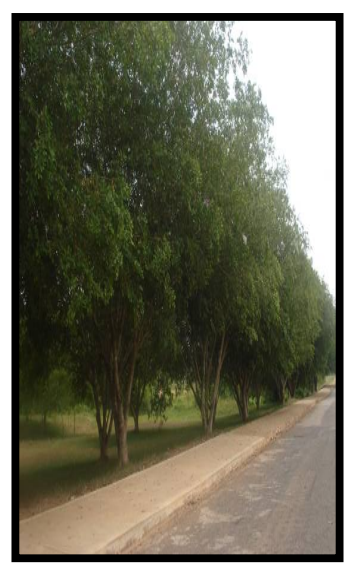

Figura 2. Via de acesso às dependências do Campus/UFAC arborizado com ingá-mirim

Figure 2. Entry road to university dependencies forested with

João R. A. Leão et al.. 
Figura 3. Aspecto da folha composta de ingá- mirim

Figure 3. Leaf of ingá- mirim

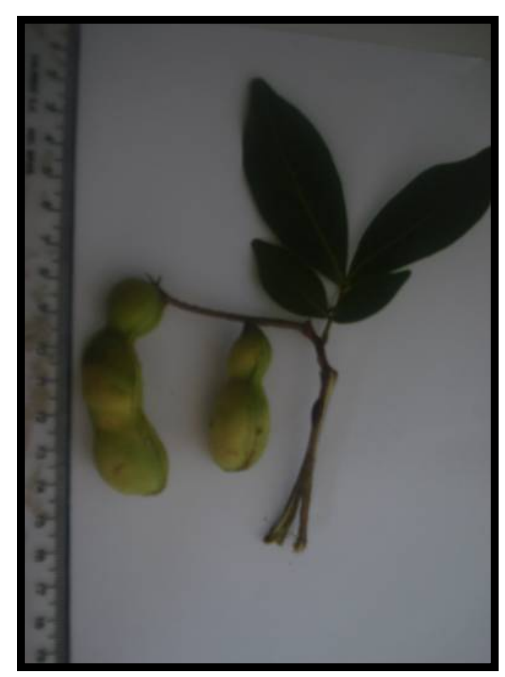

As suas sementes são recalcitrantes, com nível de germinação satisfatório. A I. laurina tem um interesse econômico devido o uso da madeira e ao seu fruto.

A avaliação do crescimento de mudas em diferentes composições de resíduos agroflorestais, como substrato, visa produzir mudas mais vigorosas e com menor custo, usando matéria prima regional alternativa. Os bons resultados obtidos por Leão \& Paiva (2009) com Andira inermis (W.Wright) DC. subsp. inermis (sucupira); por Dumont (2009) com Cedrela odorata L.(cedro rosa); por Lima et al. (2006) com Ricinus communis L. (mamoneira) corroboram tal hipótese.

$\mathrm{Na}$ Amazônia ocidental pesquisas relacionadas à utilização destes substratos vêm sendo realizadas no intuído de dar uma destinação correta a estes resíduos que se tornariam poluentes, utilizando-os no desenvolvimento
Figura 4. Aspecto do fruto de ingá- mirim

Figure 4. Fruit of de ingá- mirim

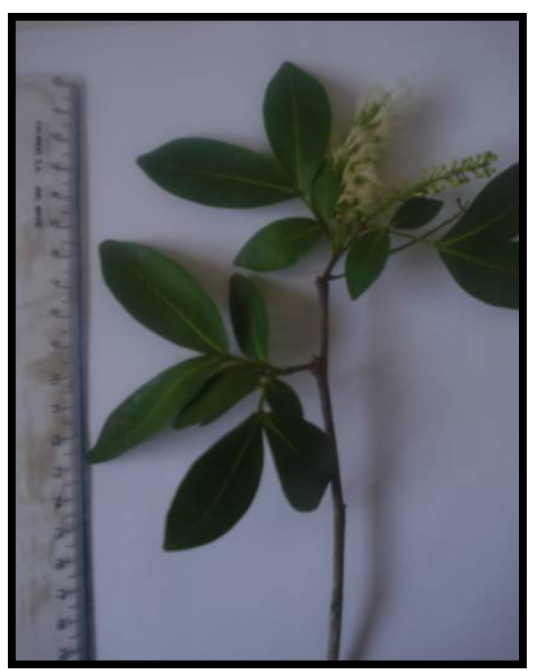

de mudas de melhor qualidade, melhorando o processo produtivo e contribuindo com a preservação do meio ambiente (MARANHO;PAIVA, 2009; LEÃO;PAIVA, 2010).

Portanto, foi objetivo desta pesquisa estudar a germinação de sementes e crescimento inicial de plântulas desta espécie nativa, frequentemente utilizada na arborização urbana, em resposta à diferentes substratos compostos por resíduos agroflorestais.

\section{MATERIAL E MÉTODOS}

Este trabalho foi realizado na casa de vegetação e no laboratório de análise de sementes florestais do Parque Zoobotânico (PZ) da Universidade Federal do Acre (UFAC). As sementes de ingá-mirim foram coletadas de três árvores matrizes localizadas no campus da Universidade Federal do Acre, que abrange uma área de aproximadamente 300 hectares e situa-se na região leste do Estado do Acre, as margens da BR-364, distando 10 km do centro de Rio Branco, capital do Estado (6762’W, $\left.10^{\circ} 07^{\prime} \mathrm{S}\right)$.

A coleta das sementes ocorreu no mês de janeiro de 2010 diretamente nas árvores, posteriormente as sementes foram beneficiadas para remoção do arilo. Como as 
sementes desta espécie são recalcitrantes, logo após a etapa de beneficiamento o experimento foi instalado.

\section{Instalação do experimento}

O experimento foi instalado e conduzido sobre as bancadas de madeira em condições ambientais da casa de vegetação. Foram utilizados os seguintes substratos (Figura 5): areia, como testemunha (1:1), casca de amendoim triturada (1:1), casca de castanha-do-brasil triturada (1:1), resíduo de açaí peneirado (1:1), colocados em bandejas plásticas com dimensões de 25x39x7,5 cm, em seguida ocorreu à semeadura das sementes selecionadas, com quatro repetições de 25 sementes cada, contendo 100 sementes em cada bandeja. Os substratos foram irrigados diariamente com regador manual.

Do início ao término do experimento, do mês de janeiro ao mês de março, foram observadas a Temperatura e a Umidade Relativa (UR\%), que apresentaram uma média de $33,95^{\circ} \mathrm{C}$ e $70,44 \%$ respectivamente.

\section{Avaliações da qualidade fisiológica das sementes}

Os seguintes parâmetros foram avaliados:

A) Porcentagem de Germinação - onde se considerou como plântulas germinadas as que apresentaram um par de folhas bem definidas ao final do teste, ou seja, trinta e quatro dias após a instalação do experimento.

B) Índice de Velocidade de Germinação (IVG) - foram realizadas contagens diárias das plântulas germinadas com um par de folhas bem definidas, durante 34 dias, o índice foi calculado conforme a fórmula proposta por (MAGUIRE, 1962).

C) Comprimento da Parte Aérea e Comprimento da Raiz - ao final do experimento foram retiradas 10 plântulas consideradas germinadas de cada bandeja ao acaso por repetição. O comprimento da parte aérea foi medido com uma régua graduada em centímetros medindo-se do colo até a gema apical. Para medição da raiz utilizou-se a mesma régua medindo-se do colo até a extremidade final da raiz primária.

D) Massa Verde - após as medições foi feita à pesagem da massa verde da parte aérea e da raiz, separadamente, em balança analítica com precisão de três casas decimais (MARCONI BG-400).

E) Massa Seca - a raiz e a parte aérea das plântulas foram acondicionadas em sacos de papel, previamente identificadas, e levadas para secar em estufa regulada a temperatura de $65{ }^{\circ} \mathrm{C}$, onde permaneceu até atingir peso constante, de acordo com os bons resultados obtidos (PAIVA et al., 2009). Decorrido o período para a desidratação o material foi pesado em balança analítica com precisão de três casas decimais (MARCONI BG400).

F) Número de folhas e de folíolos - Antes de ir à secagem foi quantificado o número de folhas e folíolos das 10 plântulas retiradas de cada repetição.

Figura 5. Resíduos agroflorestais: Resíduo de açaí peneirado (A), casca de amendoim triturada (B) e casca de castanha-do-brasil triturada (C). Figure 5. Agroforest residues: Açai residue sifted (A), peanut rind freaked (B) e Brazil nut freaked (C).

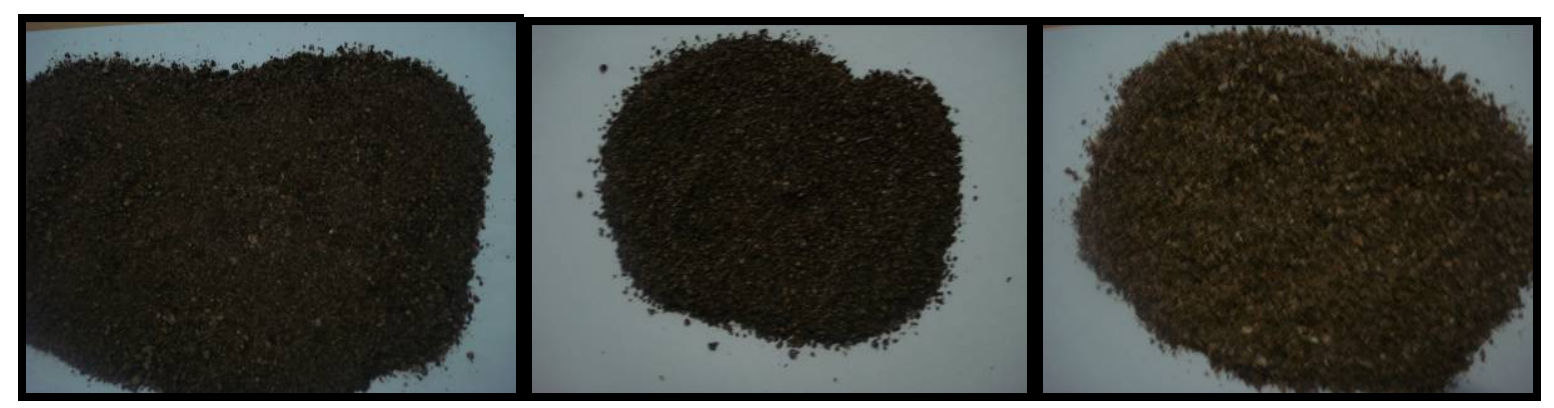

João R. A. Leão et al.. 


\section{Procedimento estatístico}

No experimento, foi utilizado o delineamento experimental inteiramente casualizado (DIC), constando de quatro tratamentos com quatro repetições de 25 sementes cada. Os dados foram submetidos ao teste da normalidade de distribuição dos erros e de homogeneidade da variância, e as médias comparadas pelo teste de Tukey em nível de 5\% de probabilidade. O programa estatístico utilizado na análise dos dados foi o Assistat versão 7.5. Os valores de porcentagem de germinação foram transformados em arc sen $(\mathrm{x} / 100) 0,5$ (BANZATTO e KRONKA, 2006).

\section{RESULTADOS E DISCUSSÕES}

Os resultados de porcentagem de germinação e o índice de velocidade de germinação - IVG das sementes de ingá-mirim são apresentados na Tabela 1. Para a variável germinação observa-se que não houve diferença significativa. Verifica-se que as sementes de ingá-mirim apresentaram a mesma capacidade de germinação e produção de plântulas nos diferentes tipos de substratos compostos por resíduos agroflorestais. Diante disto, reafirma-se a natureza recalcitrante e alta germinabilidade, características estas presentes nas espécies do gênero Inga (RODRIGUES et al., 2007).

Resultado similar foi encontrado por Bonjovani \& Barbedo (2008) estudando a germinação de sementes recalcitrantes de Inga vera Willd. subsp. affinis (DC.) T. D. Penn. em rolos de papel e em baixas temperaturas sem secagem das sementes. Segundo Alvino e Rayol (2007) a areia apresenta desuniformidade de retenção e distribuição de água, características essas que podem ter influenciado nos resultados da germinação das sementes. Com relação ao índice de velocidade de germinação IVG da espécie, os resultados demonstram que as sementes apresentaram velocidade de germinação não significativa. Resultados diferentes destes foram obtidos no estudo realizado por Rodrigues et al., (2007) em relação ao índice de velocidade de germinação - IVG com o substrato vermiculita em diferentes níveis de umidades diferiram estatisticamente na germinação de sementes de ingá-mirim (Inga laurina (S W.) Willd) Leguminosae. Ao analisar-se a Tabela 2 verifica-se que em relação ao comprimento da parte aérea, foi observada diferença significativa para o tratamento com resíduo de açaí. Este substrato apresentou como resultado de sua utilização uma superioridade em termos de comprimento da parte aérea aos tratamentos utilizando areia, casca de amendoim triturada, casca de castanha-do-brasil triturada permitindo uma maior formação de área fotossintética, com consequente, maior desenvolvimento das plântulas. Resultados semelhantes foram encontrados por Maranho \& Paiva (2010) ao estudar o desenvolvimento de mudas de Itaúba-de-capoeira (Physocalymma scaberrimum Pohl - Lythraceae) em substrato composto por diferentes porcentagens de resíduo orgânico de açaí, dados não publicados.

TABELA 1. Porcentagem de germinação e índice de velocidade de germinação de ingá-mirim (Inga laurina (S W.) Willd) aos 34 dias após semeadura, avaliados em experimento realizado na casa de vegetação da Universidade Federal do Acre, em Rio Branco, Acre, 2010.

\begin{tabular}{lcc}
\hline Substratos & Germinação (\%) & IVG \\
\hline Areia & $90,00 \mathrm{a}$ & $19,24 \mathrm{a}$ \\
Casca de amendoim & $99,00 \mathrm{a}$ & $20,71 \mathrm{a}$ \\
Casca de castanha-do-brasil & $97,00 \mathrm{a}$ & $20,00 \mathrm{a}$ \\
Resíduo de açaí & $100,00 \mathrm{a}$ & $19,91 \mathrm{a}$ \\
CV $(\%)$ & 7,03 & 8,50 \\
\hline
\end{tabular}


Médias seguidas de mesma letra não diferem entre si pelo teste Tukey ao nível de 5\% de probabilidade.

Analisando o comprimento das raízes, foi constatado que os substratos não influenciaram estatisticamente neste parâmetro. Porém, sabe-se que o crescimento das raízes das plântulas permite uma maior absorção de água e de nutrientes favorecendo o desenvolvimento vegetativo. É comum as plântulas investirem mais na parte aérea, dependendo da disponibilidade de nutrientes no substrato.

Tabela 2. Comprimento da parte aérea e da raiz de ingá-mirim (Inga laurina (S W.) Willd) aos 34 dias após semeadura, avaliados em experimento realizado na casa de vegetação da Universidade Federal do Acre, em Rio Branco, Acre, 2010.

Table 2. Length of shoot and root of de ingá-mirim (Inga laurina (S W.) Willd) at 34 days after sowing, evaluate in study realized in green house at Federal University of Acre, Rio Branco, Acre, 2010.

\begin{tabular}{lcc}
\hline Substratos & \multicolumn{2}{c}{ Comprimentos } \\
\cline { 2 - 3 } & Parte Aérea (cm) & Raiz (cm) \\
Areia & $18,28 \mathrm{~b}$ & $18,27 \mathrm{a}$ \\
Casca de amendoim & $5,73 \mathrm{c}$ & $10,15 \mathrm{a}$ \\
Casca de castanha-do-brasil & $21,44 \mathrm{~b}$ & $11,21 \mathrm{a}$ \\
Resíduo de açaí & $35,83 \mathrm{a}$ & $11,99 \mathrm{a}$ \\
CV (\%) & 27,92 & 31,28 \\
\hline
\end{tabular}

Médias seguidas de mesma letra não diferem entre si pelo teste Tukey ao nível de 5\% de probabilidade.

Os dados da Tabela 3 expressam os resultados referentes à massa de matéria verde da parte aérea, observa-se que houve diferença significativa entre os tratamentos testados, sendo que, os melhores resultados foram obtidos pelo substrato areia (Figura 6 e 7). Os substratos casca de amendoim triturada, casca de castanha-do-brasil triturada e resíduo de açaí obtiveram os valores mais baixos de massa de matéria verde da parte aérea.
Figura 6. Qualidade da plântula de ingá-mirim em areia Figure 6. Quality of ingá-mirim seedling in sand

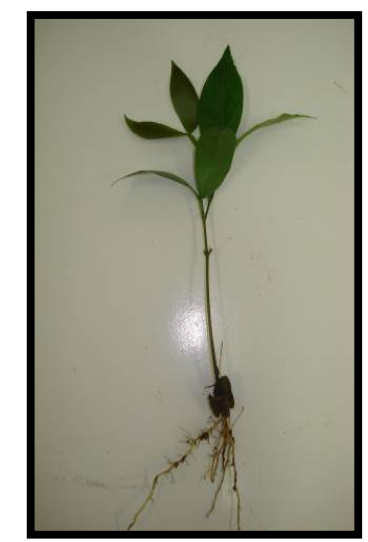

Soc. Bras. de Arborização Urbana
Figura 7. Vigor de plântulas de ingá-mirim em areia

Figure 7. Vigor of ingá-mirim seedling in sand

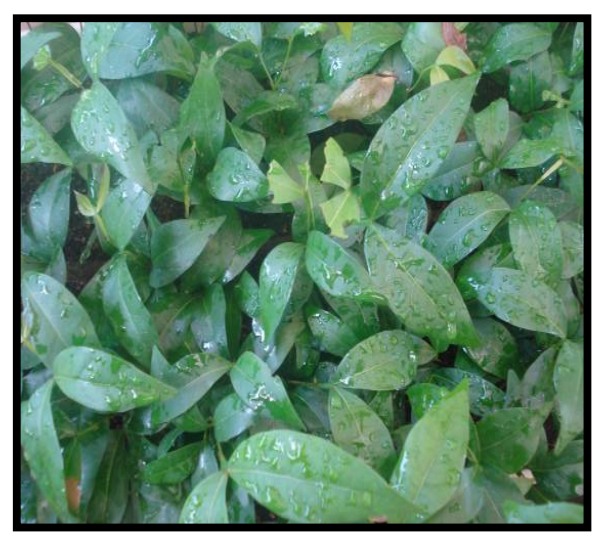

João R. A. Leão et al.. 
Resultados diferentes foram obtidos por Pereira (2009) ao estudar o efeito de diferentes substratos na germinação e no vigor de sementes de ipê roxo - Tabebuia impetiginosa (Mart.) Standl, onde o substrato areia apresentou resultado inferior.

Em relação à massa de matéria seca da parte aérea (Tabela 3), não se observou diferença estatística para os substratos avaliados. Contudo, sabe-se que a transferência de matéria seca dos tecidos de reserva para o eixo embrionário na fase de germinação, origina plântulas com maior peso, em função do maior acúmulo de massa seca (NAKAGAWA, 1999).

A massa de matéria verde da raiz das plântulas (Tabela 4) apresentou resultados semelhantes quanto aos substratos testados.
Dumont (2009) estudando efeito de diferentes substratos na germinação de sementes de cedro rosa - Cedrela odorata L. (Meliaceae) observou os mesmos resultados para o substrato areia, o que também concorda com os resultados obtidos neste trabalho.

Os melhores resultados de massa de matéria seca da raiz das plântulas (Tabela 4) foram obtidos com o substrato areia que apresentou resultados superiores aos demais tratamentos. Os demais substratos conferiram o valor mais baixo de massa de matéria seca da raiz. Resultados diferentes foram obtidos por Marques et al., (1999) testando os substratos palha de arroz, serragem e vermiculita para a germinação de pau rosa (Aniba rosaeodora Ducke).

Tabela 3. Massa de matéria verde e seca da parte aérea de ingá-mirim (Inga laurina (S W.) Willd) aos 34 dias após semeadura, avaliados em experimento realizado na casa de vegetação da Universidade Federal do Acre, em Rio Branco, Acre, 2010

Table 3. Fresh weight and dry of shoot of ingá-mirim (Inga laurina (S W.) Willd) at 34 days after sowing, evaluate in study realized in green house at Federal University of Acre, Rio Branco, Acre, 2010

\begin{tabular}{lcc}
\hline Substratos & \multicolumn{2}{c}{ Parte Aérea } \\
\cline { 2 - 3 } Areia & Massa Verde (g) & Massa Seca (g) \\
\cline { 2 - 3 } Casca de amendoim & $8,99 \mathrm{a}$ & $2,54 \mathrm{a}$ \\
Casca de castanha-do-brasil & $6,31 \mathrm{~b}$ & $\mathrm{a}$ \\
Resíduo de açaí & $7,67 \mathrm{ab}$ & $1,17 \mathrm{a}$ \\
CV (\%) & $7,28 \mathrm{ab}$ & 38,01 \\
\hline
\end{tabular}

Médias seguidas de mesma letra não diferem entre si pelo teste Tukey ao nível de 5\% de probabilidade

Tabela 4. Massa de matéria verde e seca da raiz de ingá-mirim (Inga laurina (S W.) Willd) aos 34 dias após semeadura, avaliados em experimento realizado na casa de vegetação da Universidade Federal do Acre, em Rio Branco, Acre, 2010

Table 4. Fresh weight and dry of root of ingá-mirim (Inga laurina (S W.) Willd) at 34 days after sowing, evaluate in study realized in green house at Federal University of Acre, Rio Branco, Acre, 2010

\begin{tabular}{lcc}
\hline Substratos & \multicolumn{2}{c}{ Raiz } \\
\cline { 2 - 3 } & Massa Verde (g) & Massa Seca (g) \\
Areia & $2,24 \mathrm{a}$ & $1,89 \mathrm{a}$ \\
Casca de amendoim & $2,20 \mathrm{a}$ & $0,83 \mathrm{~b}$ \\
Casca de castanha-do-brasil & $2,71 \mathrm{a}$ & $0,82 \mathrm{~b}$ \\
Resíduo de açaí & $3,06 \mathrm{a}$ & $0,91 \mathrm{~b}$ \\
CV $(\%)$ & 20,23 & 37,34 \\
\hline
\end{tabular}

Médias seguidas de mesma letra não diferem entre si pelo teste Tukey ao nível de 5\% de probabilidade 
Na Tabela 5 observa-se a variável analisada, o número de folhas e de folíolos submetidos a diferentes tipos de substratos compostos por resíduos agroflorestais, onde houve diferença significativa entre as médias dos tratamentos estudados. O substrato que apresentou o melhor resultado foi areia (3,83 folhas e 7,73 folíolos) tendo sua superioridade verificada em relação aos tratamentos casca de amendoim triturada, casca de castanha-do-brasil triturada e resíduo de açaí. Logo o número de folhas é um bom parâmetro no vigor de plântulas, pois plantas com maior número de folhas podem ser favorecidas na produção de fotoassimilados (VENTURI;PAULILO, 1988). Segundo Martins-Corder \& Saldanha (2006) a produção de substâncias necessárias para o crescimento das plantas está diretamente relacionado à quantidade de folhas. $\mathrm{O}$ fato de esta espécie colonizar naturalmente áreas ripárias de rios em sua região de ocorrência, sobre substratos arenosos, muitas vezes em bancos de areia, pode explicar este bom desempenho.

Tabela 5. Número de folhas e folíolos de ingá-mirim (Inga laurina (S W.) Willd) aos 34 dias após semeadura, avaliados em experimento realizado na casa de vegetação da Universidade Federal do Acre, em Rio Branco, Acre, 2010.

Table 5. Leaves number and leaflets of ingá-mirim (Inga laurina (S W.) Willd) at 34 days after sowing, evaluate in study realized in green house at Federal University of Acre, Rio Branco, Acre, 2010.

\begin{tabular}{lcc}
\hline Substratos & \multicolumn{2}{c}{ Quantificação } \\
\cline { 2 - 3 } & Folhas & Folíolos \\
Areia & $3,83 \mathrm{a}$ & $7,73 \mathrm{a}$ \\
Casca de amendoim & $3,08 \mathrm{~b}$ & $6,02 \mathrm{~b}$ \\
Casca de castanha-do-brasil & $3,15 \mathrm{~b}$ & $6,18 \mathrm{~b}$ \\
Resíduo de açaí & $2,95 \mathrm{~b}$ & $6,00 \mathrm{~b}$ \\
CV (\%) & 6,97 & 7,35 \\
\hline
\end{tabular}

Médias seguidas de mesma letra não diferem entre si pelo teste Tukey ao nível de 5\% de probabilidade

\section{CONCLUSÃO}

- O substrato resíduo de açaí apresentou os melhores resultados para comprimento da parte aérea.

- Para massa de matéria verde da parte aérea o substrato areia mostrou-se ideal.

- Para porcentagem de germinação, de IVG, massa de matéria seca da parte aérea, de massa de matéria verde da raiz e de comprimento da raiz não houve diferenças significativas na determinação dos resultados nos diversos tratamentos testados.

- O maior crescimento número de folhas e folíolos foi obtido no tratamento areia.

\section{AGRADECIMENTOS}

À equipe da Unidade de Tecnologia de alimentos UTAL que ajudaram na trituração dos substratos.

Aos pesquisadores do Laboratório de Sementes do Parque Zoobôtanico - PZ/UFAC que auxiliaram nas análises de biomassa.
Aos funcionários de Viveiro de mudas da UFAC que apoiaram a execução desta pesquisa.

João R. A. Leão et al.. 


\section{REFERENCIAS BIBLIOGRÁFICAS}

ALVINO, F. de O.; RAYOL, B. P. Efeito de diferentes substratos na germinação de Ochroma pyramidale (Cav. ex Lam.) Urb. (Bombacaceae). Ciência Florestal, Santa Maria, v.17, n. 1, p. 71-75, jan-mar. 2007.

BANZATTO, D. A.; KRONKA, S. do N. Experimentação agrícola. 4. ed. Jaboticabal: Funep, 2006. 237 p.

DUMONT, M. L. Efeito de diferentes substratos na germinação de sementes de cedro rosa - Cedrela odorata $\mathbf{L}$. (Meliaceae) em casa de vegetação. 2009. 40 f. Monografia (Graduação em Engenharia Florestal) - Centro de Ciências Biológicas e da Natureza, Universidade Federal do Acre, Rio Branco, AC, 2009.

GODOY, A. L. P. Cidade e Meio Ambiente: o Planejamento da Arborização de Pirassununga/SP. Dissertação. Mestrado. Rio Claro, IGCE/UNESP, 2001.

JACINTO, J. M. M. Análise silvicultural urbana de seis espécies florestais utilizadas na arborização de Brasília. 2001. Dissertação de mestrado em Ciências Florestais. Universidade de Brasília. Faculdade de Tecnologia. Departamento de Engenharia Florestal. DF. 2001.

LEÃO, J. R. A.; PAIVA, A. V. de. Utilização de resíduos agroflorestais como substrato no desenvolvimento de mudas de Andira inermis (W.Wright) DC. subsp. inermis. In: CONGRESSO INTERNACIONAL DE TECNOLOGIAS PARA O MEIO AMBIENTE, 2., 2010. Bento Gonçalves. Anais... Bento Gonçalves: FIEMA, 2010. 1 CD-ROM.

LIMA, R. de L. S. de; SEVERINO, L. S.; SILVA, M. I. de L.; JERÔNIMO, J. F.; VALE, L. S. do; BELTRÃO, N. E. de M. Substratos Para Produção de Mudas de Mamoneira Compostos por Misturas de Cinco Fontes de Matéria Orgânica. Ciênc. agrotec., Lavras, v. 30, n. 3, p. 474-479, maio/jun., 2006.

LORENZI, H. Árvores Brasileiras - Manual de Identificação e Cultivo de Plantas Arbóreas Nativas do Brasil. V.2. $2^{\text {a }}$ Ed. Editora Plantarum. Nova Odessa - SP. 368 p. 2002.

MAGUIRE, J. D. Speed of germination: aid in selectionand evaluation for seedling emergence and vigor. CropScience, Madison, v. 2, n. 2, p. 176-177, 1962.

MARANHO, A. S; PAIVA, A. V. Germinação de sementes e desenvolvimento de mudas de supiarana - Alchornea discolor poepp. - em substrato composto por diferentes porcentagens de resíduo orgânico de açaí. In: CONGRESSO BRASILEIRO DE ARBORIZAÇÃO URBANA, 13., 2009, Rio Branco. Anais... Rio Branco: UFAC, 2009. 1 CD-ROM.

MARQUES, A. da S. J.; VARELA, V. P.; MELO, Z. L. de O. Influência da cobertura e do sombreamento do canteiro na germinação de plântulas de pau rosa (Aniba rosaeodora). Acta amazônica, Manaus, v. 29, n. 2, p. 303-312, 1999. Disponível em: <http:// acta.inpa.gov.br/fasciculos/29 2/PDF/v29n2a11.pdf>. Acesso em: 19 jan. 2010.

MARTINS-CORDER, M. P.; SALDANHA, C. W. Germinação de sementes e crescimento de plântulas de diferentes progênies de Euterpe edulis Mart. Revista Árvore, Viçosa, v.30, n.5, p. 693-699, 2006.

MELO, M. S. da; PIRES, N. A. M. T.; OLIVEIRA, D. E. de; SANTOS, S. X. Diagnóstico da arborização urbana no município de Goiandira, Goiás. In: SEMINÁRIO DE INICIAÇÃO CIENTÍFICA, 4., 2006, Anápolis. Anais... Anápolis: UEG, 2006.p. 268. Disponível em: <http://www.prp.ueg.br/06v1/conteudo/pesquisa/iniccien/eventos/sic2006/arquivos/biologicas/diagnostico_arborizacao.pdf>. Acesso em: 20 jan. 2010.

NAKAGAWA, J. Testes de vigor baseados no desempenho das plântulas. In: KRZYZANOWSKI, F. C.; VIEIRA, R. D.; FRANÇA NETO, J. B. (Eds.) Vigor de sementes: conceitos e testes. Londrina: ABRATES, 1999. p. 2.1-2.24.

PAIVA, A. V. de; POGGIANI, F.; GONÇALVES, J. L. de M.; FERRAZ, A. de V. Crescimento de mudas de espécies arbóreas nativas, adubadas com diferentes doses de lodo de esgoto seco e com fertilização mineral. Sci. For., Piracicaba, v. 37, n. 84, p. 499-511, dez. 2009.

PEREIRA, T. F. Efeito de diferentes substratos na germinação e no vigor de sementes de ipê roxo - Tabebuia impetiginosa (Mart.) Standl, (Bignoniaceae) em casa de vegetação. 2009. 37 f. Monografia (Graduação em Engenharia Florestal) - Centro de Ciências Biológicas e da Natureza, Universidade Federal do Acre, Rio Branco, AC, 2009.

RODRIGUES, C. M.; FERREIRA, W. R.; LIMA, J. A. de; DORNELLES, M. C.; RANAL, M.; SANTANA, D. G. de. Germinação de embriões de duas espécies de Inga (Mimosaceae). Revista Brasileira de Biociências, Porto Alegre, v.5, supl. 2, p. 561-563, jul. 2007. Disponível em: <http://www6.ufrgs.br/seerbio/ojs/index.php/rbb/article/viewfile/492/429.pdf.> Acesso em: 20 jan. 2010.

VENTURI,S.; PAULILO, M. T. S. Esgotamento das reservas na semente de Euterpe edulis Mart. e efeito da nutrição mineral nas plântulas. Acta Botânica Brasílica, Porto Alegre, v.12, n.3, p.215-220, 1998.

GERMINAÇÃO DE SEMENTES E CRESCIMENTO... 